\title{
Makna Satire Tersembunyi dalam Iklan (Analisis Semiotika Roland Barthes pada Iklan A Mild Versi Bukan Main)
}

\author{
Stephen Jaufarry ${ }^{1}$, Lusia Savitri Setyo Utami** \\ ${ }^{1}$ Fakultas Ilmu Komunikasi Universitas Tarumanagara \\ Email: jaufarry@gmail.com \\ ${ }^{2}$ Fakultas Ilmu Komunikasi Universitas Tarumanagara* \\ Email:lusias@fikom.untar.ac.id
}

Masuk tanggal: 15-12-2021, revisi tanggal: 06-01-2022, diterima untuk diterbitkan tanggal: 16-01-2022

\begin{abstract}
This research discusses the hidden meaning of satire in the Bukan Main version of A Mild advertisement. Today many social problems occur in Indonesian society, such as violations of rules and ethics that have been established by the community. Regarding these social problems, A Mild's product made an advertisement with the title Bukan Main to insult the Indonesian people who violated the rules. Based on this background, this research's problem formulation is how the meaning of satire is depicted in the Bukan Main version of A Mild advertisement. The research objective is to find out and describe the satire's meaning in the advert A Mild version of not playing. The theoretical review used is advertising, semiotics, and satire. This study using a qualitative approach with Roland Barthes' semiotic analysis. The meaning of satire is obtained from a multilevel meaning; this idea is known as the "order of signification," which includes denotation (real meaning) and connotation (multiple meanings) and then ends in myth. This study's results indicate myths such as not caring about others, not caring about the environment, not being disciplined, and problems with social status. The conclusion is that the Bukan Main version of A Mild's ad has a hidden satire meaning that people are still not aware of and behave following existing norms or regulations.
\end{abstract}

Keyword: advertising, satire, semiotic

\begin{abstract}
Abstrak
Penelitian ini membahas tentang makna satire tersembunyi dalam iklan A Mild versi Bukan Main. Pada masa sekarang banyak terdapat masalah sosial yang terjadi di masyarakat Indonesia seperti pelanggaran aturan dan etika yang sudah ditetapkan oleh masyarakat. Melihat permasalahan sosial tersebut maka produk A Mild membuat iklan dengan judul Bukan Main untuk menyindir masyarakat Indonesia yang melanggar aturan. Rumusan masalah penelitian ini adalah bagaimana makna satire yang digambarkan dalam iklan A Mild versi Bukan Main. Tujuan penelitian adalah untuk mengetahui dan mendeskripsikan makna satire yang digambarkan dalam iklan A Mild versi Bukan Main. Tinjauan teoritis yang digunakan adalah periklanan, semiotika dan satire. Penelitian ini menggunakan pendekatan kualitatif dengan analisis semiotika Roland Barthes. Makna satire tersebut diperoleh dari pemaknaan bertingkat, gagasan ini di kenal dengan istilah order of signification yaitu yang mencakup denotasi (makna sesungguhnya) dan konotasi (makna ganda) lalu berujung pada mitos. Hasil penelitian ini menunjukan mitos seperti kurang peduli dengan orang lain, tidak peduli lingkungan, tidak disiplin, dan masalah status sosial. Kesimpulannya, dalam iklan A Mild versi Bukan Main terdapat makna satire tersembunyi bahwa masyarakat masih belum menyadari dan berperilaku sesuai dengan norma-norma atau peraturan yang ada.
\end{abstract}

Kata Kunci: periklanan, satire, semiotika 


\section{Pendahuluan}

Satire merupakan suatu gaya bahasa untuk menyatakan sindiran atau kritikan kepada seseorang atau suatu keadaan. Gaya bahasa satire sendiri mempunyai sifat yang menertawakan, menolak, dan mengkritik. Satire pada dasarnya ungkapan sindiran yang secara halus dan tidak kasar sehingga dapat menjadi suatu lelucon (Keraf, 2010). Dalam penggunaannya satire sendiri bukan hanya sebagai cara untuk menyindir seseorang atau suatu keadaan. Dalam kata-kata satire sendiri mengandung pesan yang ingin disampaikan kepada khalayak banyak.

Di dalam iklan, satire sering kali digunakan untuk memperkenalkan produk perusahaan dan tidak jarang untuk memberikan suatu kritik terhadap suatu keadaan. Iklan yang menggunakan gaya bahasa satire sendiri dianggap kreatif karena mempunyai tujuan untuk memberikan suatu kritikan ke arah yang lebih membangun. Iklan adalah bagian penting dari serangkaian kegiatan mempromosikan produk yang menekankan unsur citra. Dengan demikian, objek iklan tidak sekedar tampil dalam wajah yang utuh, akan tetapi melalui proses pencitraan, sehingga citra produk lebih mendominasi daripada produk itu sendiri (Wibobo dan Kharimah, 2012).

Advertiser rokok menampilkan konsep iklan yang berbeda dengan iklan lainnya, iklan ini menampilkan keunikan tersendiri dengan jalan cerita yang unik dan menarik, iklan A Mild versi Bukan Main ini mengangkat cerita tentang masalahmasalah sosial yang ada di tengah-tengah masyarakat yang tidak mencerminkan norma-norma yang berlaku. Iklan A Mild versi Bukan Main ini dikemas dengan terdapat setiap sindiran di setiap adegannya. Dalam menampilkan masalah sosial yang terjadi, advertiser berusaha menceritakan produk mereka bahwa sebagai produsen yang peduli dengan banyak permasalahan yang terjadi di Indonesia ini. Dalam iklan tersebut, peneliti ingin meneliti tentang gaya satire tersembunyi yang terdapat dalam setiap adegan yang mengandung makna satire tersembunyi. Makna satire tersembunyi yang terdapat dalam iklan A Mild versi Bukan Main memungkinkan akan dimaknai lebih dalam melalui analisis semiotik.

Semiotika adalah ilmu atau metode analisis yang fokusnya untuk mengkaji sebuah tanda dan makna. Pada dasarnya ilmu ini mempertanyakan sesuatu penyampaian pesan yang kurang jelas dan harus dipahami lebih lanjut, semiotika sebagai suatu model dari ilmu-ilmu sosial yang memahami dunia sebagai sistem hubungan yang memiliki tanda-tanda didalamnya (Sobur, 2006).

Dengan menggunakan gagasan Barthes yaitu order of signification yang mencakup denotasi (makna sesungguhnya) dan konotasi (makna ganda). Barthes menggunakan istilah signifier (penanda) dan signified (petanda) dan berujung pada mitos yang diusung oleh Saussure (Krisyanto 2009:32). Penelitian ini akan memperlihatkan makna satire tersembunyi yang terdapat dalam iklan A Mild versi Bukan Main. Iklan ini mengandung sindiran yang menargetkan masyarakat, setiap adegan dibalut dengan unsur humor dengan fokus agar masyarakat dapat memahami makna pesan secara mendalam.

Dari iklan ini maka peniliti, merasa perlu untuk melakukan analisis semiotika dalam iklan A Mild versi Bukan Main.

\section{Metode Penelitian}

Jenis penelitian yang digunakan dalam penelitian ini adalah penelitian kualitatif. Menurut Sugiyono (2011), metode penelitian kualitatif adalah metode yang 
berdasarkan pada filsafat postpostivisme. Metode yang digunakan penelitian ini adalah studi kasus dan teknik pengolahan data yang digunakan dengan menggunakan semiotika model Roland Barthes seperti makna denotasi, makna konotasi, dan mitos yang digunakan untuk memahami makna yang terkandung dalam setiap scene iklan A Mild versi Bukan Main.

Subjek dari penelitian ini adalah iklan A Mild Versi Bukan Main, data yang diperoleh adalah gambar atau kata-kata dan nantinya akan dibagi lagi menjadi potongan-potongan scene untuk dianalisis sedangkan Objek, individu, situasi dan peristiwa tidak mempunyai penafisirannya sendiri (Noriega, 2020). Oleh karena itu obyek penelitian adalah makna satire yang terdapat dalam iklan A Mild versi Bukan Main.

Dalam penelitian ini, peneliti menggunakan teknik keabsahan data triangulasi. Triangulasi data merupakan teknik pemeriksaan data yang menggunakan berbagai sumber data seperti dokumen, arsip, hasil observasi atau juga dengan mewawancarai lebih dari satu subjek yang dianggap memiliki sudut pandang yang berbeda.

Tabel 1. Peta Tanda Roland Barthes

\begin{tabular}{cc}
\hline \multicolumn{2}{c}{ 1. Signifier (Petanda) } \\
\hline \multicolumn{2}{c}{ 3. Denotative sign (tanda denotatif) } \\
\hline $\begin{array}{c}\text { 4. Connotative Signifier (Penanda } \\
\text { Konotatif) }\end{array}$ \\
\hline \multicolumn{2}{c}{ 6. Connotative Sign (Tanda Konotatif) }
\end{tabular}

Sumber: Alex Sobur (2013)

Secara langsung penjelasan Barthes mempunyai tiga tahap signifikasi yaitu: Signifiknasi tingkat pertama (Denotasi), Signifikansi tingkat kedua (Konotasi) dan Signifikansi tingkat ketiga (Mitos).

\section{Hasil Temuan Dan Diskusi}

Tabel 2. Hasil Analisis

Teks: Kita ngerasa udah maju nyatanya gini-gini aja

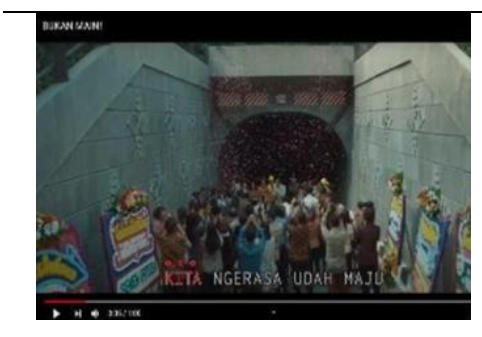

Makna Denotasi Tingkat Pertama

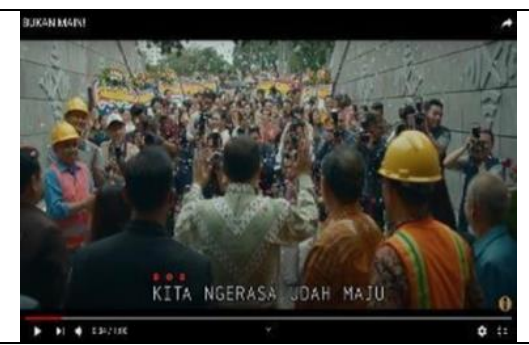

Signifier: Seorang pejabat yang meresmikan suatu bangun dan setelahnya banyak sampah dan banyak coretan di tembok-tembok

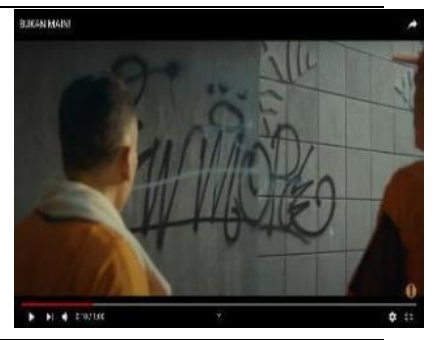

Signified: Menonjolkan sikap yang ingin maju tapi masih banyak orang yang belum maju dalam tindakan seperti mencoret-coret tembok 


\begin{tabular}{lll}
\hline Makna Denotasi Tingkat Kedua & $\begin{array}{l}\text { Signfier: Menonjolkan sikap yang } \\
\text { ingin maju tapi masih banyak } \\
\text { orang yang belum maju dalam } \\
\text { tindakan seperti mencoret-coret } \\
\text { tembok }\end{array}$ & $\begin{array}{l}\text { fasilitas umum dengan } \\
\text { baik sulit dilakukan } \\
\text { karena kurangnya } \\
\text { kesadaran akan } \\
\text { kebersihan }\end{array}$ \\
\hline Mitos & \multicolumn{2}{l}{$\begin{array}{l}\text { Konsep kurangnya untuk menghargai usaha orang lain dan } \\
\text { kedisiplinan dalam kebersihan }\end{array}$} \\
\hline
\end{tabular}

Sumber: Pengolahan Data oleh Peneliti

Tabel 3. Hasil Analisis

\section{Teks: Sering gengsi duluan urusan laper bisa belakangan}
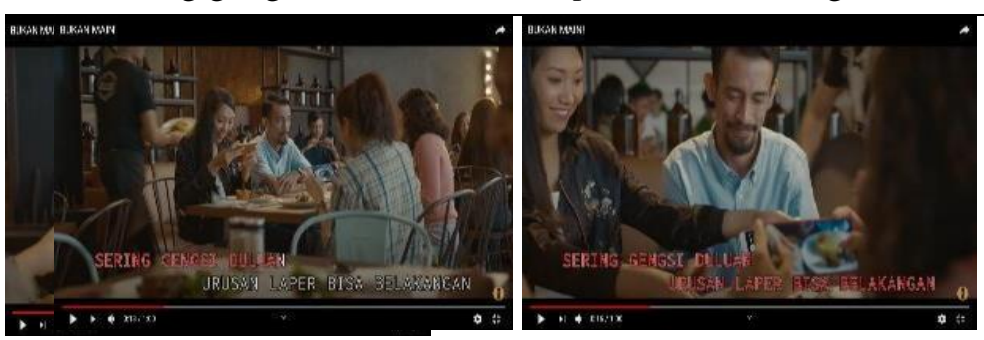

Makna Denotasi Tingkat Signifier: Memperlihat kan adegan Signified: Terlihat seorang Pertama

kegiatan makan bersama dengan

kerabat dan teman-temannya wanita mengambil gambar makanan dan seorang pria dengan raut muka yang kesal

\begin{tabular}{lll}
\hline Makna Denotasi Tingkat & $\begin{array}{l}\text { Signfier: Terlihat seorang wanita } \\
\text { Kengambil gambar makanan dan } \\
\text { seorang pria dengan raut muka } \\
\text { yang kesal }\end{array}$ & $\begin{array}{l}\text { Signified: Sikap tidak } \\
\text { menghargai kebersamaan dan } \\
\text { mengumbar makanan mewah } \\
\text { dengan tujuan menaikan } \\
\text { status sosial di sosial media }\end{array}$ \\
\hline Mitos & $\begin{array}{l}\text { Status sosial seseorang ditentukan oleh makanan yang orang } \\
\text { tersebut makan, makin sering mengunggah makanan mahal } \\
\text { makin tinggi status sosial orang tersebut }\end{array}$ \\
\hline
\end{tabular}

Sumber: Pengolahan Data oleh Peneliti

Tabel 3. Hasil Analisis

Teks: Sering kali lo yang salah kok lo yang galak

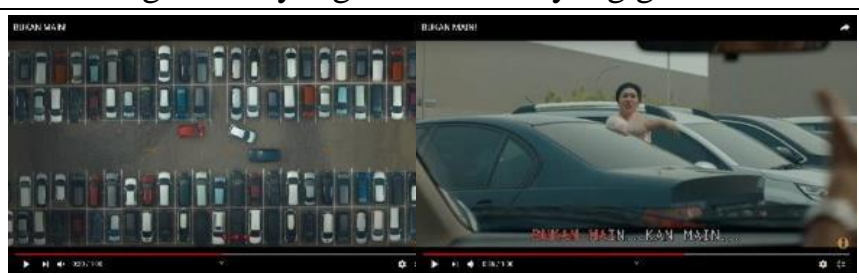

Makna Denotasi Signifier: Memperlihatkan seorang Tingkat Pertama wanita berdebat dengan seorang pria saat sedang memakirkan mobilnya masing-masing

Signified: Terlihat seorang wanita dengan raut muka marah sambil memarahi seorang pria di dalam mobil 


\begin{tabular}{ll}
\hline $\begin{array}{l}\text { Makna Denotasi } \text { Signfier: Terlihat seorang wanita } \\
\text { Tingkat Kedua }\end{array}$ & $\begin{array}{l}\text { Signified: Marah duluan saat } \\
\text { dengan raut muka } \\
\text { marah sambil memarahi seorang pria di mempunyai kesalahan } \\
\text { dalam mobil }\end{array}$ \\
\hline Titos & Tidak disiplin dan kurang intropeksi diri \\
\hline Sumber: Pengolahan Data oleh Peneliti
\end{tabular}

Tabel 4. Hasil Analisis

Teks: Cinta sama keindahan bodo amat sama kebersihan

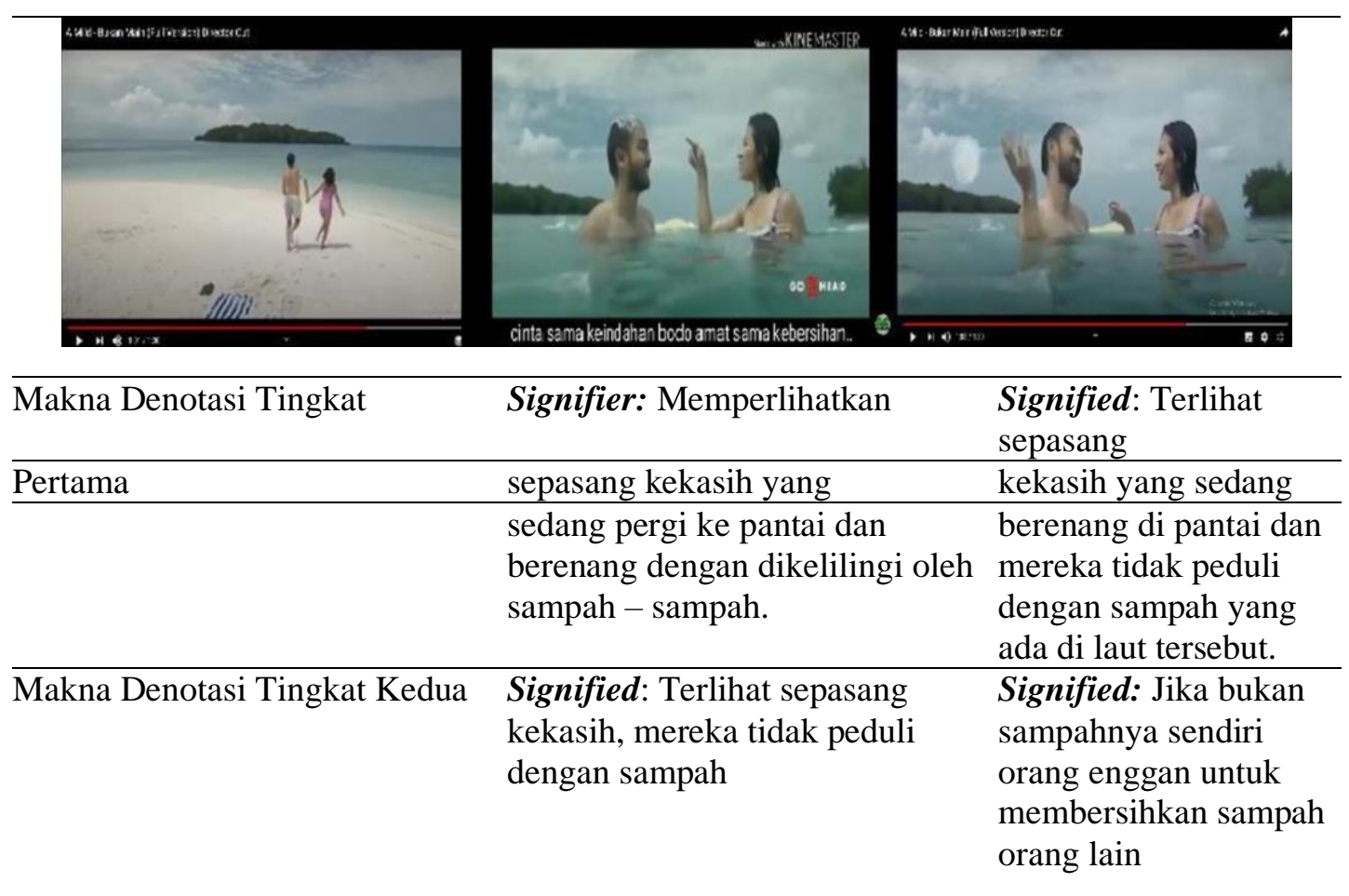

Mitos

Sikap acuh dan tidak peduli lingkungan

Sumber: Pengolahan Data oleh Peneliti

Tabel 5. Hasil Analisis

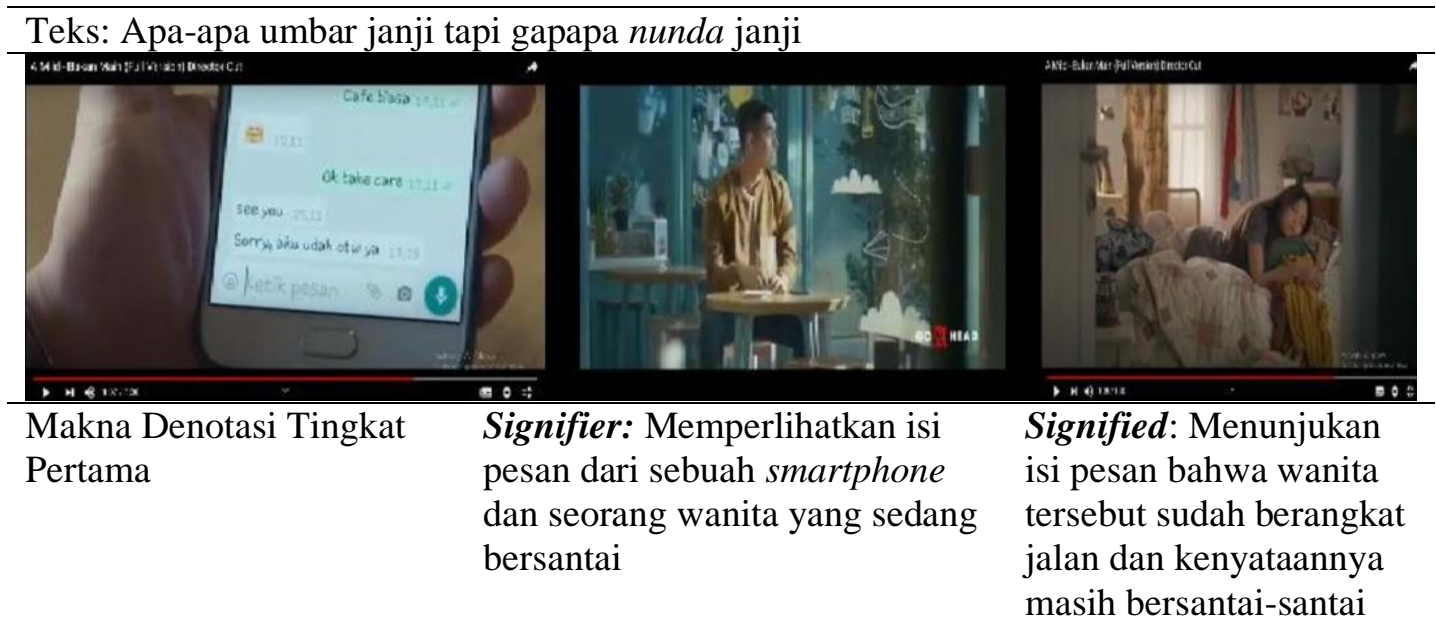

\begin{tabular}{lll}
\hline Makna Denotasi Tingkat & Signifier:Menunjukan isi pesan & Signified: Sikap tidak
\end{tabular} 


\begin{tabular}{lll}
\hline Kedua & $\begin{array}{l}\text { bahwa wanita tersebut sudah } \\
\text { berangkat jalan dan } \\
\text { kenyataannya masih bersantai- } \\
\text { santai }\end{array}$ & $\begin{array}{l}\text { terus terang dan } \\
\text { berbohong untuk } \\
\text { menutupi kesalahan }\end{array}$ \\
\hline Mitos & $\begin{array}{l}\text { Mitos: Jika tidak ingin mendapat masalah orang akan } \\
\text { berbohong agar terhindar dari masalah }\end{array}$ \\
\hline
\end{tabular}

Sumber: Pengolahan Data oleh Peneliti

Tabel 6. Hasil Analisis

Teks: Inilah cerita jutaan orang yang bukan main

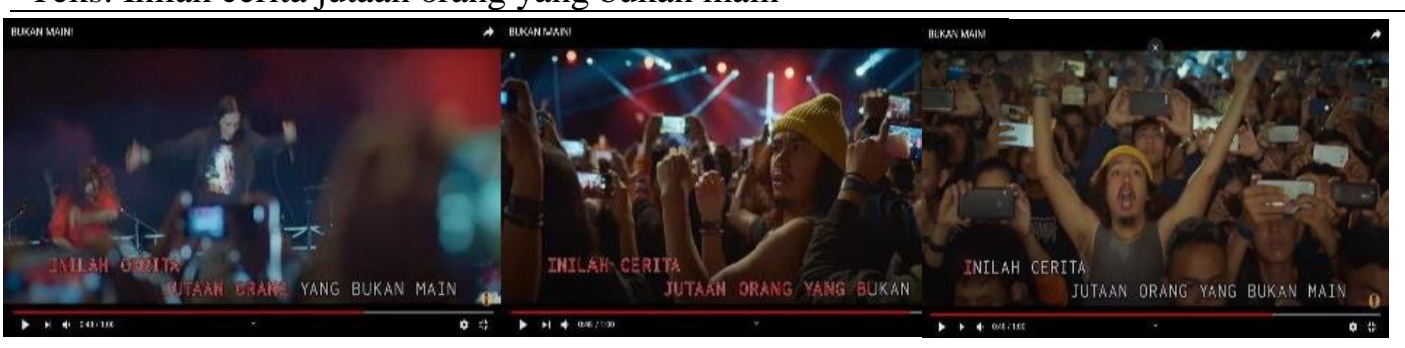

Makna Denotasi Tingkat Pertama
Signifier: Sebuah band melakukan konser yang di tonton para penggemarnya yang sibuk merekam
Signified: Menunjukan band tersebut susah susah payah untuk menghibur penonton yang ada di acara tersebut tetapi penonton hanya sibuk dengan konten sosial media

Makna Denotasi Tingkat Kedua
Signified: Menunjukan band tersebut susah susah payah untuk menghibur penonton yang ada di acara tersebut tetapi penonton hanya sibuk dengan konten sosial media
Signfier: Konten untuk sosial media masing-masing orang lebih penting dibandingkan dengan menikmati acaranya Sikap acuh dan tidak menghargai usaha orang lain dalam Mitos hal menghibur

Sumber: Pengolahan Data oleh Peneliti

Menurut Ade Nurdin, Yani Maryani dan Mumu (2012) satire adalah gaya bahasa yang berbentuk penolakan dan mengandung kritikan dengan maksud agar sesuatu yang salah itu dicari kebenarannya. Maka dalam iklan ini terdapat munculnya mitos dan makna satire seperti:

1. Mitos pada scene pertama adalah konsep kurangnya untuk menghargai usaha orang lain dan kedisiplinan dalam kebersihan.

2. Mitos pada scene kedua adalah status sosial seseorang ditentukan oleh makanan yang orang tersebut makan, makin sering mengunggah makanan mahal makin tinggi status sosial orang tersebut.

3. Mitos pada scene ketiga adalah menunjukan tidak disiplin dan kurang intropeksi diri dari temuan mitos tersebut melihatkan bahwa tidak dispinlin dalam mengantri.

4. Mitos pada scene keempat adalah sikap acuh dan tidak peduli lingungan.

5. Mitos pada scene kelima adalah jika tidak ingin mendapat masalah orang akan berbohong agar terhindar dari masalah.

6. Mitos pada scene keenam adalah sikap acuh dan tidak menghargai usaha orang lain dalam hal menghibur. 
Melalui temuan mitos yang ditemukan maka terdapat makna satire tersembunyi seperti:

1. Konsep kurangnya untuk menghargai usaha orang lain dan kedisiplinan dalam kebersihan menyindir masyarakat yang ingin maju tapi sikapnya sendiri yang membuat tidak maju.

2. Status sosial seseorang ditentukan oleh makanan yang orang tersebut makan, menyindir kepada masyarakat bahwa gengsi di media sosial lebih penting disbanding kebersamaan.

3. Menunjukan tidak disiplin dan kurang intropeksi diri menyindir masyarakat bahwa masih banyak yang tidak menaati aturan dan norma yang ada.

4. Sikap acuh dan tidak peduli lingungan menyindir masyarakat yang kurang peduli dengan alam dan lingkungan sekitar.

5. Jika tidak ingin mendapat masalah orang akan berbohong agar terhindar dari masalah menyindir masyarakat yang kurang sadar akan menepati janji dan menghargai waktu.

6. Sikap acuh dan tidak menghargai usaha orang lain dalam hal menghibur menyindir masyarakat yang hanya mementingkan konten media sosialnya.

Makna satire pada scene pilihan 1,2,3,4,5 dan 6 merupakan makna satire yang menargetkan masyarakat dan Makna satire yang dibalut dengan humor juga diperlihatkan dalam scene pilihan 2,3 dan 5.

Secara garis besar, adapun makna satire yang bisa kita tangkap dari penjabaran tabel-tabel di atas bahwa produsen dari iklan A Mild versi Bukan Main mengisyaratkan produk mereka bisa memberikan pesan kepada masyarakat bahwa dalam sindiran-sindiran tersebut dapat mengubah moral masyarakat dapat menjadi lebih baik dan menerapkan aturan dengan tepat.

\section{Simpulan}

Melihat mitos-mitos yang ditampilkan dalam pembahasan maka terdapat makna satire tersembunyi yang berusaha disampaikan kepada masyarakat. Makna satire yang tersembunyi ini adalah memberikan sindiran kepada masyarakat banyak bahwa kurangnya kesadaran akan menerapkan kedisiplinan dan menjaga fasilitas umum dengan baik.

Adanya mitos yang menunjukan bahwa status sosial seseorang masih lebih penting dari pada suatu kebersamaan. Makna satire tersembunyi yang ingin terungkap adalah sindiran kepada banyak orang bahwa pengakuan dari orang lain lebih penting dibandingkan dengan menjaga sikap kebersamaan dan menghargai orang lain. Adanya temuan mitos yang menunjukan bahwa kurangnya kesadaran untuk memperhatikan orang lain dan memperhatikan lingkungan sekitar. Makna satire tersembunyi yang terungkap adalah sindiran kepada orang-orang bahwa kurangnya memperhatikan lingkungan dan menjaga alam dengan baik.

Jadi, dilihat dari iklan A Mild versi Bukan Main ini menunjukkan makna satire tersembunyi dapat dilihat bahwa masyarakat masih belum menyadari dan berperilaku sesuai dengan norma-norma atau peraturan yang ada. Penelitian ini merekomendasikan masyarakat agar lebih memahami makna isi pesan yang disampaikan agar masyarakat lebih menaati aturan dan menjaga lingkungan sekitar dan alam. 


\section{Ucapan Terima Kasih}

Penulis mengucapkan banyak terima kasih kepada setiap pihak yang telah membantu penulis dalam menyelesaikan penelitian ini.

\section{Daftar Pustaka}

Ade Nurdin, Y. M. (2012). Intisari Bahasa dan Sastra Indonesia. Bandung: Pustaka Setia.

Alex (2013) Semiotika Komunikasi. Bandung. Rosdakarya Sobur, Alex (2012) Analisis Teks Media. Jakarta: Remaja Rosdakarya

Keraf, G. (2010). Diksi dan Gaya Bahasa. Jakarta: PT Gramedia Pustaka Utama

Noriega, O. (7 Januari 2020). Satirisme Cerdas Iklan Djarum 76 Filter Gold Versi Caleg Cerdas (Analisis Semiotika Roland Barthes). Diakses dari https://journal.untar.ac.id/index.php/prologia/article/view/6438/4974

Sugiyono (2011) Metode Penelitian Kuantitatif Kualitatif dan $R \& D$. Alfabeta.

Sugiyono (2012) Memahami Penelitian Kualitatif. Bandung: Alfabeta. Sobur,

Sobur, Alex (2006). Semiotika Komunikasi Analisis Teks Media Suatu Pengantar untuk Analisa Wacana, Analisis Semiotik, dan Analisis framing. Bandung: PT Remaja Rosdakarya.

Wibowo, S. F. \& Karimah, M. P. (2012). Pengaruh Iklan Televisi dan Harga terhadap Keputusan Pembelian Sabun LUX (survei pada pengunjung Mega Bekasi Hypermall). Jurnal Riset Manajemen Sains Indonesia (JRMSI), Vol. 3, No.1 